\title{
Transcriptomic and metabolomic analyses reveal that bacteria promote plant defense during infection of soybean cyst nematode in soybean
}

\author{
Wenshu Kang ${ }^{1}$, Xiaofeng Zhu', Yuanyuan Wang ${ }^{2}$, Lijie Chen ${ }^{1}$ and Yuxi Duan ${ }^{1 *}$ (D)
}

\begin{abstract} Nematicidal metabolites

\section{Background}

Soybean is a crucial crop and a sustainable source of protein and oil worldwide. Soybean cyst nematode (SCN) is one of the most devastating pathogens in soybean that causes significant production losses. Possible countermeasures include resistant varieties, crop rotation, nematicides, and biological control [1]. Of these, chemical nematicides are generally not recommended for controlling SNC because of their non-selective nature, low efficiency, and high cost [2, 3]. In contrast, there are many advantages to using microbial control agents, including no impact to humans or other nontarget organisms, decreased pesticide residues in food, conservation of natural enemies, and improvement of ecological diversity [4].
\end{abstract}

Background: Soybean cyst nematode $(\mathrm{SCN})$ is the most devastating pathogen of soybean. Our previous study showed that the plant growth-promoting rhizobacterium Bacillus simplex strain Sneb545 promotes soybean resistance to SCN. Here, we conducted a combined metabolomic and transcriptomic analysis to gain information regarding the biological mechanism of defence enhancement against SCN in Sneb545-treated soybean. To this end, we compared the transcriptome and metabolome of Sneb545-treated and non-treated soybeans under SCN infection.

Results: Transcriptomic analysis showed that 6792 gene transcripts were common in Sneb545-treated and non-treated soybeans. However, Sneb545-treated soybeans showed a higher concentration of various nematicidal metabolites, including 4-vinylphenol, methionine, piperine, and palmitic acid, than non-treated soybeans under SCN infection.

Conclusions: Overall, our results validated and expanded the existing models regarding the co-regulation of gene expression and metabolites in plants, indicating the advantage of integrated system-oriented analysis.

Keywords: Soybean, Soybean cyst nematode, Bacillus simplex strain Sneb545, Transcriptome, Metabolome,

\footnotetext{
* Correspondence: duanyx6407@163.com

${ }^{1}$ Nematology Institute of Northern China, Shenyang Agricultural University, No.120 Dongling Road, Shenyang 110866, China

Full list of author information is available at the end of the article
}

Plant growth-promoting rhizobacteria (PGPR) colonise the rhizosphere of many plant species and award favourable outcomes such as increased plant development and lessened susceptibility to diseases due to plant pathogenic fungi, bacteria, viruses, and nematodes [5]. PGPR compete for an ecological niche/substrate, and produce prohibitive allelochemicals, activating induced systemic resistance (ISR) in host plants against a broad spectrum of pathogens. Additionally, several PGPR strains protect plants against pathogen infection inducing systemic resistance [6]. Previous studies showed that bacteria of the genera Pasteuria, Pseudomonas, and Bacillus are highly effective as biological control agents against nematodes [7-9]. PGPR not only colonise the rhizosphere of many plants but also can induce disease resistance through seed priming. Microbial-mediated seed priming activates ISR against nematodes [10]. In cucumber, seed treatment with Bacillus subtilis strain GB03 enhances the plant growth and resistance against Colletotrichum orbiculare, 
Pseudomonas syringae pv. Lachrymans, and Erwinia tracheiphila [11], whereas that with B. subtilis S499 activates a systemic defence response against Colletotrichum lagenarium [12] in Arabidopsis, seed treatment with B. subtilis strain GB03 activates the signalling pathway of ethylene, independently of the salicylic acid or jasmonic acid signalling pathways, triggering defence responses against Erwinia carotovora subsp. [13]; and in soybean, seed treatment with Bacillus simplex strain Sneb545 induces resistance against $\mathrm{SCN}$ [14].

Metabolomic analysis has been successfully applied, providing valuable information on plant-pathogen interactions and system-wide variations in plant metabolism under pathogen infection and allowing the identification of compounds that play a pivotal role in plant innate immunity [15-22].

In this study, we combined transcriptomic and metabolomics analysis to identify differences in gene transcript levels and metabolic pathways between Sneb545-treated and non-treated soybeans under SCN infection. The resulting data might help to better understand the underlying molecular defence mechanisms of soybean and develop more effective biological control programs against $\mathrm{SCN}$.

\section{Methods}

Plant materials, growth conditions and treatments

B. simplex strain Sneb545 was obtained from the Northern Nematode Institute, Shengyang Agriculture University, China [14] and grown on beef extract peptone agar medium at $25{ }^{\circ} \mathrm{C}$ for $48 \mathrm{~h}$. Next, a single colony was selected to inoculate $100 \mathrm{ml}$ beef extract peptone liquid medium and cultivated at $28{ }^{\circ} \mathrm{C}$ for $48 \mathrm{~h}$ on a rotary shaker at $150 \mathrm{rpm}$ [23]. The fermentation broth was added in sterile water to a final optical density of 0.377 at $560 \mathrm{~nm}$ $\left(1.0 \times 10^{9}\right.$ colony-forming unit $\left.\mathrm{ml}^{-1}\right)$.

Seeds of the susceptible soybean cultivar Liao15 were surface-sterilised in $70 \%$ ethanol for $5 \mathrm{~min}$ and $2.1 \%$ sodium hypochlorite for $12 \mathrm{~min}$ and then, rinsed three times (10 min each) in sterile distilled water [24]. Next, the seeds were homogeneously coated with Sneb545 fermentation broth (Sneb545-treated soybeans) or with sterile distilled water (non-treated soybeans) and left to naturally dry at room temperature. A diagrammatic sketch of the experimental procedure is shown in Fig. 1. The seeds were sown in plastic pots $(18 \mathrm{~cm}$ diameter $)$ that contained a sterile soil mixture (soil: sand, 1:1) and placed in a greenhouse at $26 \pm 3{ }^{\circ} \mathrm{C}$ day/night and a $16 \mathrm{~h}$ light/8 h dark cycle [23].

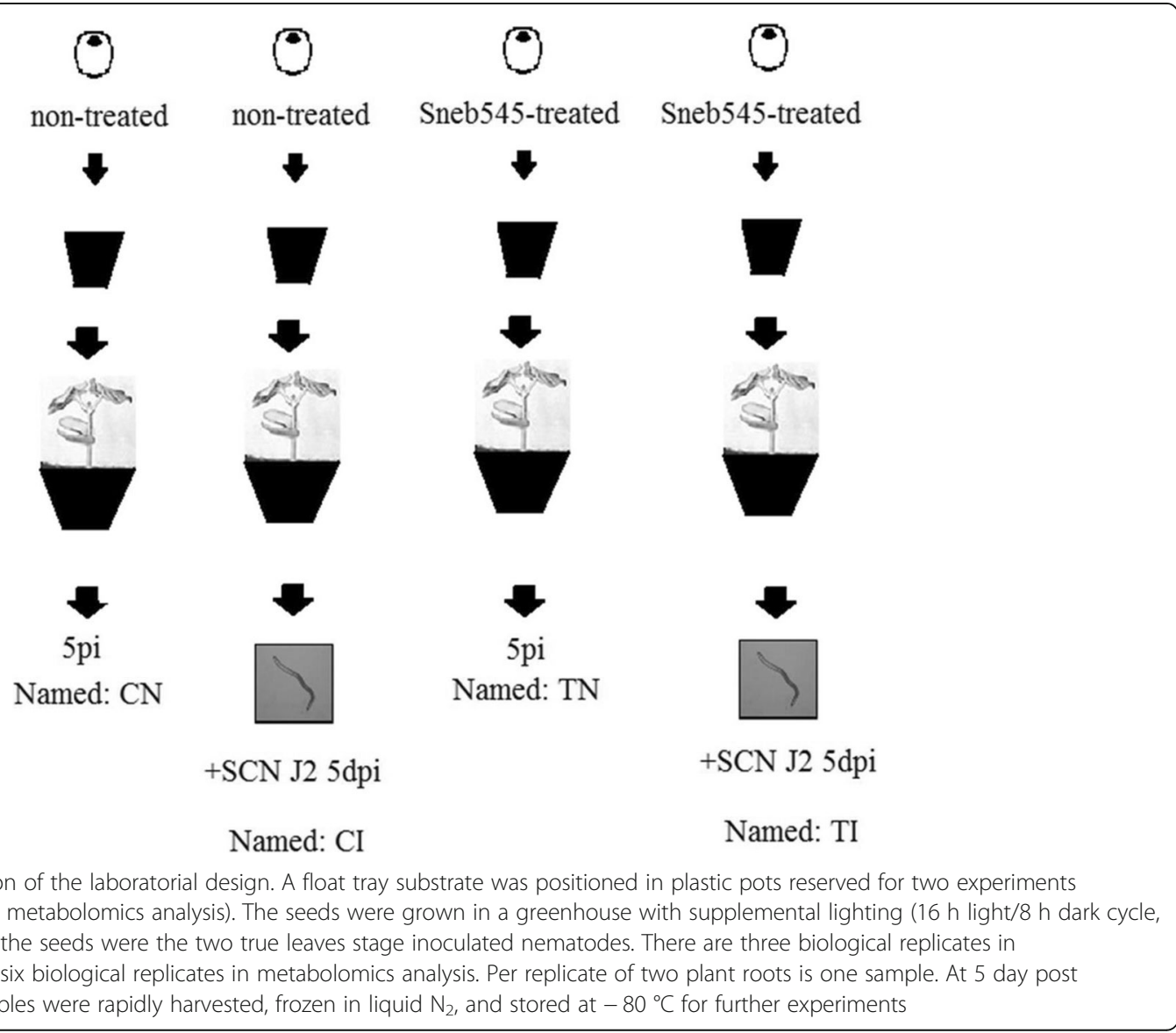


Mature females of SCN (Heterodera glycines Race 3) were harvested, and eggs were fixed as described previously [25]. Second-stage juveniles (J2) were collected to prepare $\mathrm{J} 2$ inoculum $\left(1500 \mathrm{~J}^{2} \mathrm{ml}^{-1}\right)$. Seedlings at the unifoliate stage were gently pulled out of the soil mixture and rinsed with water. Half of Sneb545-treated and nontreated soybeans were inoculated with $1 \mathrm{ml} \mathrm{J} 2$ inoculum that applied on the roots [24] to create four different treatments for analysis: Sneb545-treated soybeans infected with SCN (TI), non-treated soybeans infected with SCN (CI), Sneb545-treated soybeans not infected with SCN (TN), and non-treated soybeans not infected with SCN $(\mathrm{CN})$. Four biological replicates were used for transcriptomic analysis, whereas seven biological replicates for metabolomics analysis. At $5 \mathrm{~d}$ post infection (dpi), two roots samples per plant were harvested, immediately frozen in liquid nitrogen, and stored at $-80{ }^{\circ} \mathrm{C}$ until analysis. One replicate was stained with acid fuchsine for visualizing the infection [26]. Three biological replicates were used for transcriptomic analysis, whereas six biological replicates for metabolomics analysis.

\section{Nematode infection assay}

In $\mathrm{TI}$ and $\mathrm{CI}, \mathrm{SCN}$ development from $\mathrm{J} 2$ to third-stage juveniles (J3) was detected as described previously [26]. Data were analysed to identify any significant differences at $p<0.05 n=5$ using SPSS software 17.0.

\section{RNA extraction, library construction, and sequencing}

Frozen root tissue was milled to powder in a mortar with liquid nitrogen. Total RNA isolation was performed using RNeasy Plant Mini Kit (Qiagen, Hilden, Germany). RNA quality was tested by $1 \%$ agarose gel electrophoresis, whereas RNA purity using NanoPhotometer (IMPLEN, Westlake Village, CA, USA). RNA concentration was measured using Qubit 2.0 Fluorometer (Life Technologies, Carlsbad, CA, USA) with Qubit RNA Assay Kit. RNA integrity was assessed using Bioanalyzer 2100 (Agilent Technologies, Santa Clara, CA, USA) with RNA Nano 6000 Assay Kit (Aglient Technologies). The library construction and sequencing were performed at Novogene Corporation (http://novogene.com/index.php). The construction and sequencing of soybean cDNA libraries were performed at Novegene Company (Beijing, China; http://www.novogene.com).

\section{Data processing assembly and annotation}

Raw reads of fastq format were processed using inhouse perl scripts. Clean reads were obtained by removing those containing adapter, or ploy- $\mathrm{N}$ and as well as those of low-quality and used in all subsequent analyses. The Q20, Q30, and GC content of clean data were also calculated.
Reference genome and gene model annotation files were downloaded from (ftp://ftp.ncbi.nlm.nih.gov/genomes/all/ GCF/000/004/515/GCF_000004515.4_Glycine_max_v2.0/ GCF_000004515.4_Glycine_max_v2.0_genomic.fna.gz).

The index of the reference genome was constructed using Bowtie 2.2.3 [27] and paired-end clean reads were aligned to the reference genome using TopHat 2.0.12 [28] which can generate a database of splice junctions based on the gene model annotation file, providing better mapping results than other non-splice mapping tools.

HTSeq 0.6.1 was used to calculate the number of reads mapped to each gene. The expression level of each gene was estimated by the number of fragments per kilobase of transcript sequence per million base pairs (FPKM) that calculated based on the gene length and number of mapped reads [29].

Differential expression analysis of two groups (TI vs $\mathrm{TN}$ and $\mathrm{CI}$ vs $\mathrm{CN}$; three biological replicates per group) was performed using DESeq for R (DOI: https://doi.org/ 10.18129/B9.bioc.DESeq). KOBAS 2.0 [30] was used to test the statistical enrichment of differentially expressed genes (DEGs) in Kyto Encyclopaedia of Genes and Genomes (KEGG) pathways. The total number of genes involved in a pathway was counted and then the $p$-value was calculated using hypergeometric distribution [31].

\section{Quantitative real-time (qRT)-PCR validation}

To validate RNA-seq results, the expression patterns of 21 randomly selected genes from various functional categories and regulation patterns were analysed by qRT-PCR at five different time points post infection (Additional file 1: Table S1). Three biological replicates were collected independently and immediately frozen in liquid nitrogen. Total RNA isolation was performed as described above, and $1 \mu \mathrm{g}$ of total RNA was reversetranscribed using PrimerScript First-Strand cDNA Synthesis Kit (Takara, Dalian, China). qRT-PCR was performed in a $25 \mu \mathrm{l}$ reaction mixture containing $12.5 \mu \mathrm{l}$ $2 \times$ SYBR Master Premix ExTaq (Takara), $1 \mu \mathrm{l}$ cDNA template (1:5 dilution), and $1 \mathrm{ul}$ of each forward and reverse primer for the selected gene of interest. All primers were designed based on cDNAs using Primer Premier 5.0 (Additional file 1: Table S1). Three biological and three technical relipcates per sample were analysed using Bio-Rad Real-Time System (BioRad, Hercules, CA, USA) based on the $2^{-\triangle \Delta C T}$ method [32]. qRT-PCR conditions were $95{ }^{\circ} \mathrm{C}$ for 2 min followed 40 cycles at $95{ }^{\circ} \mathrm{C}$ for $5 \mathrm{~s}, 60{ }^{\circ} \mathrm{C}$ for $30 \mathrm{~s}$ and $65{ }^{\circ} \mathrm{C}$ for $5 \mathrm{~s}$. Actin 11 (GeneBank: 209698678) was used as a reference gene.

\section{Metabolomic analysis}

Take $50 \mathrm{mg}$ sample into the $2 \mathrm{~mL}$ EP tubes, extracted with $0.4 \mathrm{~mL}$ extraction liquid (Vmethanol: $\mathrm{VH} 2 \mathrm{O}=3: 1$ ), add $20 \mu \mathrm{L}$ of Adonitol (CAS\#: 488-81-3, $\geq 99 \%$, Sigma, 
China) $2 \mathrm{mg} / \mathrm{mL}$ stock in $\mathrm{dH} 2 \mathrm{O}$ as internal standard. Homogenized in ball millSamples for $4 \mathrm{~min}$ at $40 \mathrm{~Hz}$ used Grinding mill (JXFSTPRP-24, Shanghai, China), then ultrasound treated for $5 \mathrm{~min}$ (incubated in ice water). Centrifuge for $15 \mathrm{~min}$ at $12000 \mathrm{rpm}, 4{ }^{\circ} \mathrm{C}$. Transferred the supernatant $(0.35 \mathrm{~mL})$ into a fresh $2 \mathrm{~mL}$ gas chromatography-mass spectroscopy (GC/-MS glass vial, take $9 \mu \mathrm{L}$ from each sample and pooling as QC sample. Dry the extracts in a vacuum concentrator without heating. Add $20 \mu \mathrm{L}$ Methoxyamination hydrochloride (20 $\mathrm{mg} / \mathrm{mL}$ in pyridine), incubation for $30 \mathrm{~min}$ at $80^{\circ} \mathrm{C}$. Add $30 \mu \mathrm{L}$ of the BSTFA regent (1\% TMCS, $v / v)$ to the sample aliquots, incubated for $2 \mathrm{~h}$ at $70{ }^{\circ} \mathrm{C}$. Add $7 \mu \mathrm{L}$ FAMEs (Standard mixture of fatty acid methyl esters, C8-C16: $1 \mathrm{mg} / \mathrm{mL}$; C18-C24: $0.5 \mathrm{mg} / \mathrm{mL}$ in chloroform) to the $\mathrm{QC}$ sample it cooling to the room temperature. Mix well for GC-MS analysis.

Samples for gas chromatography-mass spectroscopy (GC-MS) were prepared as described previously [33], and analysis was performed using Agilent 7890 gas chromatograph system (Agilent Technologies) coupled with Pegasus HT time-of-flight mass spectrometer (LECO, St. Joseph, MI, USA). The system utilised a DB-5MS capillary column coated with $5 \%$ diphenyl and cross-linked with 95\% dimethylpolysiloxane ( $30 \mathrm{~m} \times 250 \mu \mathrm{m}$ inner diameter, $0.25 \mu \mathrm{m}$ film thickness; J \& W Scientific, Folsom, CA, USA). A $1 \mu \mathrm{l}$ aliquot was injected in splitless mode. Helium was used as the carrier gas, the front inlet purge flow was $3 \mathrm{ml} \mathrm{min}{ }^{-1}$, and the gas flow rate through the column was $1 \mathrm{ml} \mathrm{min}{ }^{-1}$. The initial temperature was maintained at $50{ }^{\circ} \mathrm{C}$ for $1 \mathrm{~min}$, then raised to $300{ }^{\circ} \mathrm{C}$ at a rate of $10{ }^{\circ} \mathrm{C} \mathrm{min}{ }^{-1}$, and maintained at $300{ }^{\circ} \mathrm{C}$ for $8 \mathrm{~min}$. The injection, transfer line, and ion source temperature was $280{ }^{\circ} \mathrm{C}, 270{ }^{\circ} \mathrm{C}$, and $220{ }^{\circ} \mathrm{C}$, respectively. The energy in the electron impact mode was $-70 \mathrm{eV}$. Mass spectrometry data were acquired in a full-scan mode with an $\mathrm{m} / \mathrm{z}$ range of $50-500$ at a rate of 20 spectra s$^{-1}$ after a solvent delay of $460 \mathrm{~s}$.

\section{Data analysis}

The GC/MS raw data were processed by Chroma TOF4. $3 \mathrm{X}$ (LECO) using LECO-Fiehn Rtx5 database [34]. The normalised data were used for orthogonal partial least squares discriminant analysis (OPLS-DA) by SIMCA 14 . 1 (Umea AB, Umea, Sweden).

\section{Statistical and metabolite-transcript network analysis}

One-way analysis of variance (ANOVA) in conjunction with Student's t-test was performed to determine significant differences between groups at $p<0.05$. Principal component analysis (PCA) of the total transcriptomic dataset was performed in $\mathrm{R}$ ( $\mathrm{R}$ Core Team). Transcriptome and metabolome datasets were combined to create a general metabolite-transcript network centred on genes related to phenylpropanoid biosynthesis, cysteine and methionine metabolism, tropane, piperidine and pyridine alkaloid biosynthesis, unsaturated fatty acid biosynthesis, and fatty acid metabolism according to KEGG (http://www.kegg.jp/). Structure diagrams were constructed in Microsoft Word 2010 (Microsoft Corporation, Redmond, WA, USA).

\section{Nematode mortality assessment}

The mortality rate of $\mathrm{J} 2$ at different concentrations $\left(500 \mu \mathrm{g} \mathrm{ml} l^{-1}, 600 \mu \mathrm{g} \mathrm{ml}^{-1}\right.$, and $1000 \mu \mathrm{g} \mathrm{ml}^{-1}$ ) of 4vinylphenol, L-methionine, piperine, and palmitic acid was assessed in vitro as described previously [35] and calculated as follows: ((live J2 prior to exposure - live J2 at 24 or $48 \mathrm{~h}$ post exposure)/live J2 prior to exposure) $\times$ 100. All compounds were of analytical grade and purchased from Sigma-Aldrich (St Louis, MO, USA), except for piperine that purchased from Jianglai (Shanghai, China). Each treatment was repeated in triplicate, and the experiment was repeated four times. L-methionine was dissolved in water, palmitic acid and 4-vinylphenol in 3\% Tween 80 and 4\% ethanol, whereas piperine in 3\% Tween 80 and $4 \%$ methanol. The respective diluents were used as controls. All statistical analyses were performed in SPSS software 17.0.

\section{Results}

Assessment of Sneb545-induced resistance

The ability of Sneb545 to induce soybean resistance to SCN has been recorded previously [14]. Compared with $\mathrm{CI}$, the number of nematodes in TI was lower by $72.63 \%$, whereas the ratio of nematodes in the soil adjacent to soybean roots was lower by $70.63 \%$. Except for reducing the penetration rate of nematodes, Sneb545 also inhibited the growth of nematodes in soybean roots (Fig. 2).

\section{Identification of DEGS}

In total, four separate un-normalised cDNA libraries were generated for each treatment (TI, CI, TN, and $\mathrm{CN}$ ) that produced 3.929-5.546 million clean reads per library. Of these, $94.31-99.46 \%$ of bases had a $\mathrm{Q} \geq 20$, whereas $87.29-98.14 \%$ of bases a $Q \geq 30$ (Additional file 2: Table S2). A total of 39.290-55.458 million reads from each library (80.85-92.75\% of total reads) was mapped to the reference genome (Additional file 3: Table S3). All the raw data was submitted to Sequence Read Archive database (SAMN07305253).

FPKM values were used to measure the expression level of each assembled transcript sequence in different samples, and a padj $<0.05$ was applied to identify changes in transcript abundance in the TI vs. TN and CI vs. CN group. As shown in Fig. 39661 DEGs were identified in the TI vs. TN group and 13,846 DEGs in the CI vs. CN group. Of these, 4694 and 6284 DEGs were up- 


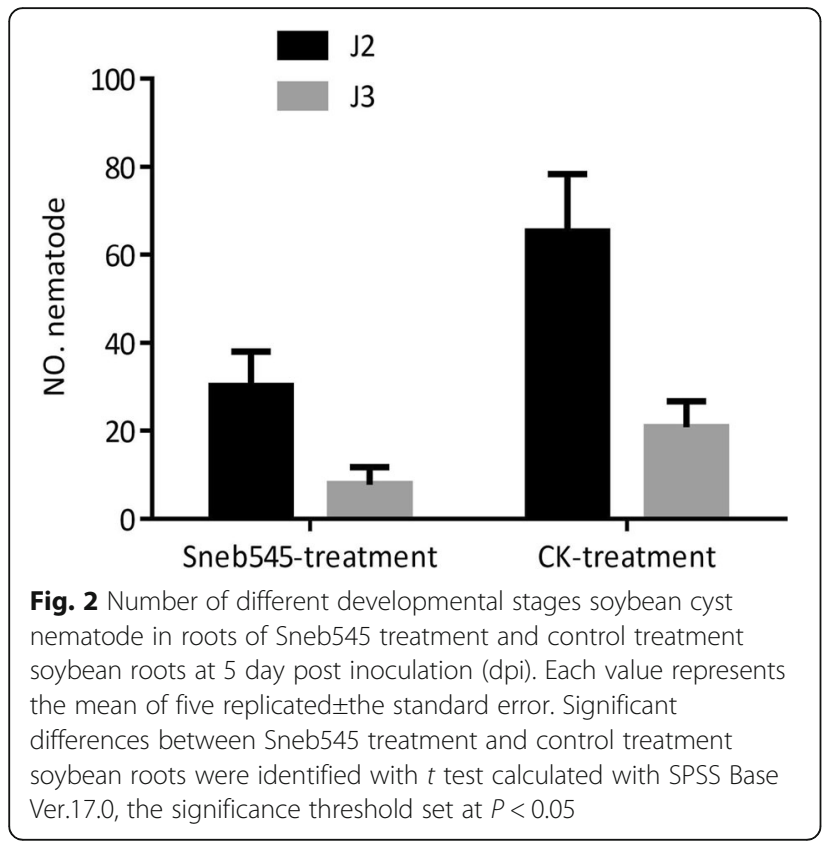

regulated, whereas 4698 and 7021 DEGs were downregulated in the TI vs. TN and $\mathrm{CI}$ vs $\mathrm{CN}$ group, respectively. Additionally, 1913 DEGs were up-regulated and 1833 down-regulated in both groups, 1746 DEGs were down-regulated in TI vs. TN group but up-regulated in
CI vs. CN group, whereas 1772 DEGs were up-regulated in the TI vs.TN group but down-regulated in the CI vs. $\mathrm{CN}$ group. The top 20 pathways for TI vs.TN group and $\mathrm{CI}$ vs.CN group are based on KEGG analyses are shown in Additional file 4: Figure S1 and Additional file 5: Figure S2.

\section{qRT-PCR}

We conducted qRT-PCR to validate the RNA-seq data and to analyze the gene expression changes of randomly selected genes at the time point $5 \mathrm{dpi}$. Although the expression levels of selected genes were different between RNA-seq and qRT-PCR, the trend of expression were the same (Additional file 1: Table S1). These genes were all down-regulated in $\mathrm{CI}$ vs $\mathrm{CN}$ group and up-regulated in TI vs TN group.

\section{Effect of Sneb545 on secondary metabolites and integrated metabolite networks}

As shown in Fig. 4, the variable importance in the projection (VIP) statistic of the first principal component of OPLS-DA model (threshold $>1$ ), together with the $p$-value of the Student's t-test (threshold $<0.05$ ) were used for selecting significant variables responsible for group separation. The level of 4-vinylphenol, Lmethionine, and palmitic acid was lower in CI than in

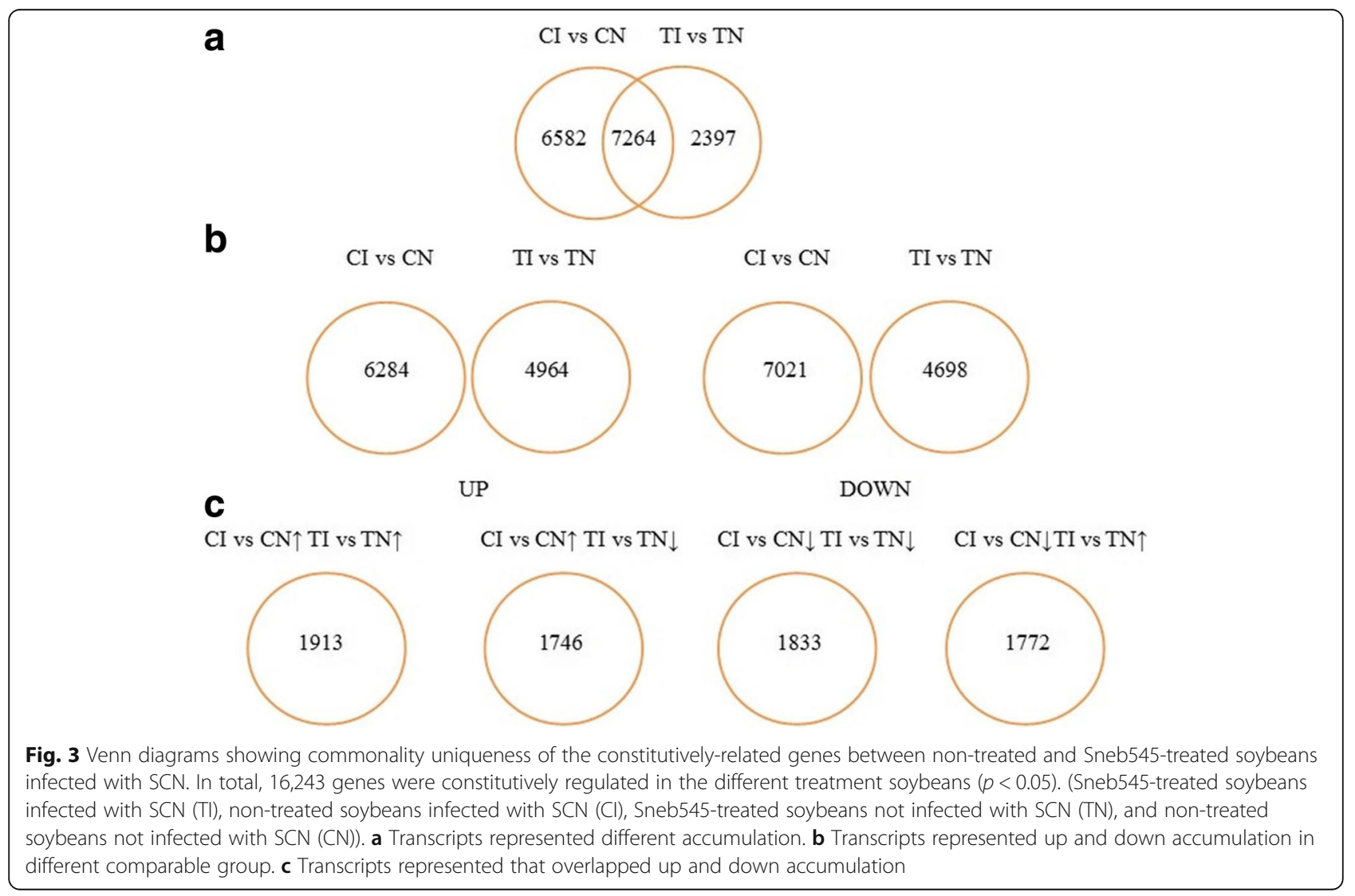



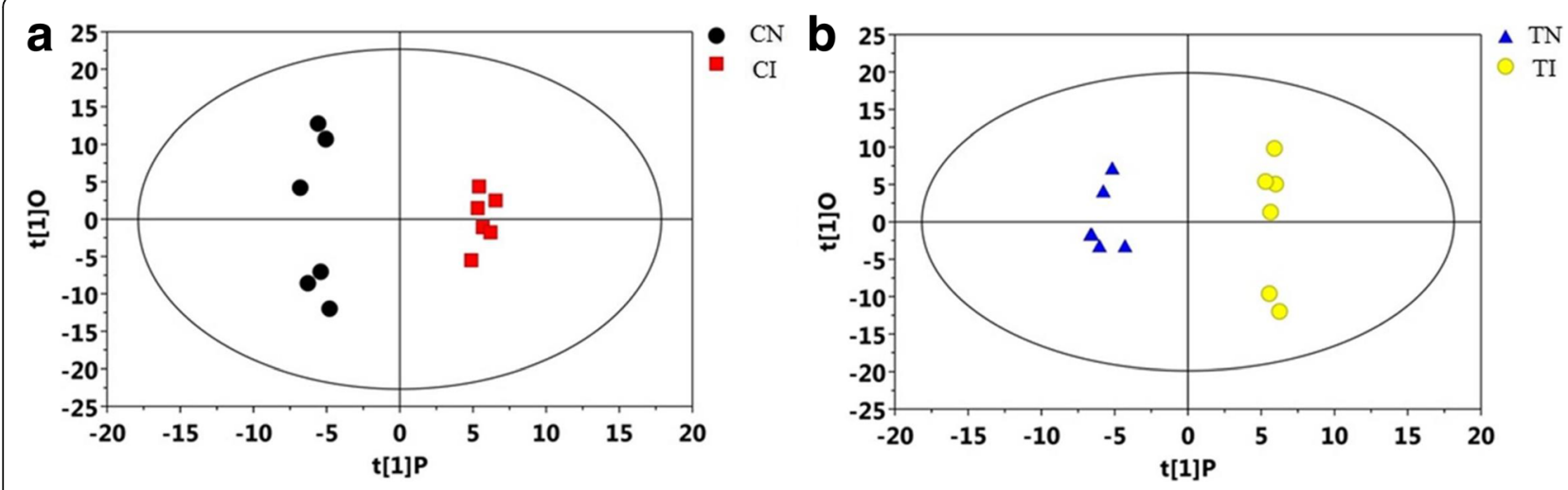

Fig. 4 OPLS-DA model analysis was performed using the most diverse sample. Sneb545-treated soybeans infected with SCN (TI), non-treated soybeans infected with SCN (Cl), Sneb545-treated soybeans not infected with SCN (TN), non-treated soybeans not infected with SCN (CN). a OPLS-DA in CI vs CN group. b OPLS-DA in TI vs TN group

$\mathrm{CN}$, but almost the same in TI and TN. However, the level of piperine was the highest in TI, followed by that in other group. Based on KEGG, the four metabolites were enriched to 20 different metabolic pathways (Additional file 6: Table S5).

\section{Comprehensive networks of transcripts and metabolites}

Using the combined transcriptomic and metabolomic data, we aimed to identify changes in KEGG pathways involving phenylpropanoid biosynthesis, cysteine and Lmethionine metabolism, tropane, piperidine, and pyridine alkaloid biosynthesis, unsaturated fatty acid biosynthesis, and fatty acid metabolism (Additional file 7: Table S6).

In the phenylpropanoid biosynthesis pathway, a cytochrome P450 CYP73A100 gene (GLYMA 20G114200) was up-regulated in the TI vs. TN group and down-regulated in the $\mathrm{CI}$ vs. $\mathrm{CN}$ group. Of three phenylalanine ammonia-lyase (PAL) genes, two (GLYMA_ $10 G 209800$ and GLYMA_10G058200) were downregulated in the $\mathrm{CI}$ vs. $\mathrm{CN}$ group and suppressed in the TI vs. TN group, whereas one (GLYMA_13G145000) was suppressed in the $\mathrm{CI}$ vs. $\mathrm{CN}$ group and up-regulated in the TI vs. TN group. Two 4-coumarate-CoA ligase (4CL) genes (GLYMA_01G232400 and GLYMA_11G010500) were suppressed in the $\mathrm{CI}$ vs. $\mathrm{CN}$ group and downregulated in the TI vs. TN group. Of 10 peroxidase (POD) genes, five (GLYMA_09G022300, GLYMA_13G307000, GLYMA_12G195500, GLYMA_10G222400, and GLYMA_ $12 \mathrm{G} 195600)$ were up-regulated in the $\mathrm{CI}$ vs. $\mathrm{CN}$ group and down-regulated in the TI vs. TN group; two (GLYMA 09G284700, and GLYMA_09G156700) were up-regulated in the CI vs. CN group and suppressed in the TI vs. TN group; whereas three (GLYMA_06G302700, GLYMA_ 01G130500, GLYMA_03G038700) were suppressed in the $\mathrm{CI}$ vs. $\mathrm{CN}$ group and down-regulated in the TI vs. TN group. Additionally, one cinnamyl alcohol dehydrogenase (CAD) gene (GLYMA_10G262400) was up-regulated in the $\mathrm{CI}$ vs. $\mathrm{CN}$ group and down-regulated in the TI vs. TN group (Fig. 5 and Additional file 7: Table S6).

In the cysteine and methionine metabolism pathway, a methionine gamma-lyase (MGL) gene (GLYMA 10G172700) was up-regulated in the CI vs. CN group and suppressed in the TI vs. TN group. Five 1aminocyclopropane-1-carboxylate synthase (ACS) genes (GLYMA_11G045600, GLYMA_11G021500, GLYMA_ 08G018000, GLYMA_05G37410, and GLYMA 07G128000) were down-regulated in both groups, but the downward fold change was higher in the TI vs. TN group. Three 1-aminocyclopropane 1-carboxylate oxidase (ACO) genes (GLYMA_15G112700, GLYMA 02G268200, and GLYMA_14G049500) were suppressed in the $\mathrm{CI}$ vs. $\mathrm{CN}$ group and down-regulated in the TI vs. TN group. Additionally, one bifunctional enzyme aspartokinase-homoserine dehydrogenase (bifunctional AKHSDH) gene (GLYMA_05G151100), one cystathionine gamma-synthase (CGS) gene (GLYMA_18G261600), and two 5-methyltetrahydropteroyltriglutamate-homocysteine methyltransferase (MET6) genes (GLYMA_17G184900, and GLYMA_19G114500) were down-regulated in the CI vs. CN group and suppressed in the TI vs. TN group (Fig. 6 and Additional file 7: Table S6).

In the tropane, piperidine, and pyridine alkaloid biosynthesis pathway, one peroxisomal copper-containing amine oxidase (CuAO) gene (GLYMA_08G282800) was suppressed in the $\mathrm{CI}$ vs. $\mathrm{CN}$ group and up-regulated in the TI vs. TN group; two spermine synthase genes were up-regulated in the TI vs. TN group and suppressed in $\mathrm{CI}$ vs. $\mathrm{CN}$ group; and one aminotransferase (ALD1) gene was up-regulated in both groups, but the upward fold change was higher in the TI vs. TN group (Fig. 7 and Additional file 7: Table S6).

In the unsaturated fatty acid biosynthesis and fatty acid metabolism pathway, one 3-oxoacyl-[acyl-carrierprotein] synthase gene (GLYMA_08G024700) was 


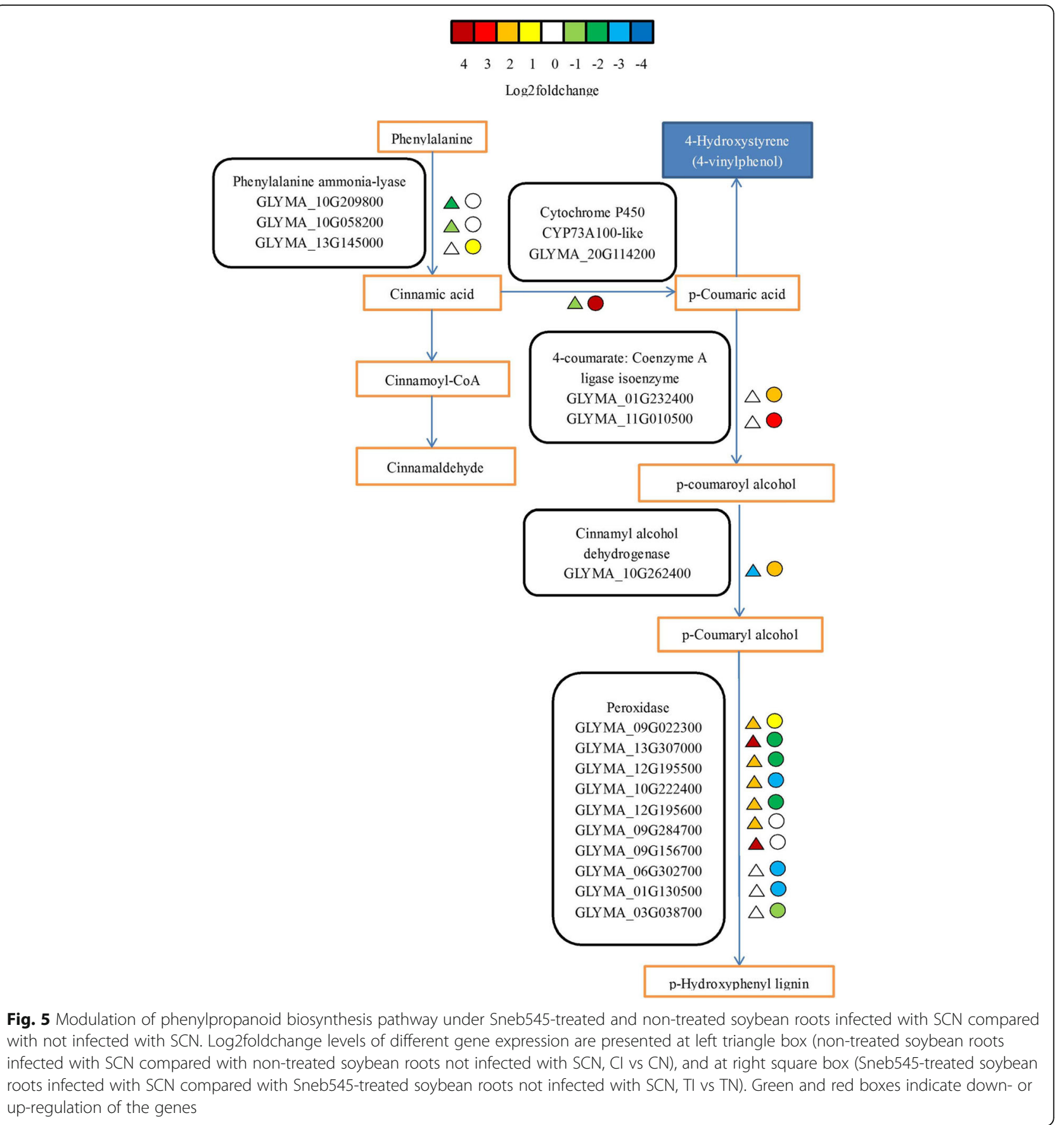

suppressed in the $\mathrm{CI}$ vs. $\mathrm{CN}$ group and up-regulated in the TI vs. TN group. Of four acyl-acyl-carrier (ACP) thioesterase genes, three (GLYMA_18G232000, GLYMA_03G009800, and GLYMA_05G012300) were down-regulated in the $\mathrm{CI}$ vs. $\mathrm{CN}$ group and one (GLYMA_03G009800) was up-regulated in the TI vs. TN group. Additionally, one enoyl-[acyl-carrier-protein] reductase (ENR) gene (GLYMA_18G156100) was down-regulated in the $\mathrm{CI}$ vs. $\mathrm{CN}$ group and suppressed in the TI vs. TN group (Fig. 8 and Additional file 7: Table S6).

\section{Nematode mortality assessment}

Nematode mortality assessment indicated that 4vinylphenol, L-methionine, piperine and palmitic acid might be effective nematicidal compounds (Table 1). At $48 \mathrm{~h}$ post treatment with L-methionine (500 $\left.\mu \mathrm{g} \mathrm{ml}^{-1}\right)$, palmitic acid $\left(600 \mu \mathrm{g} \mathrm{ml}^{-1}\right)$, 4- 


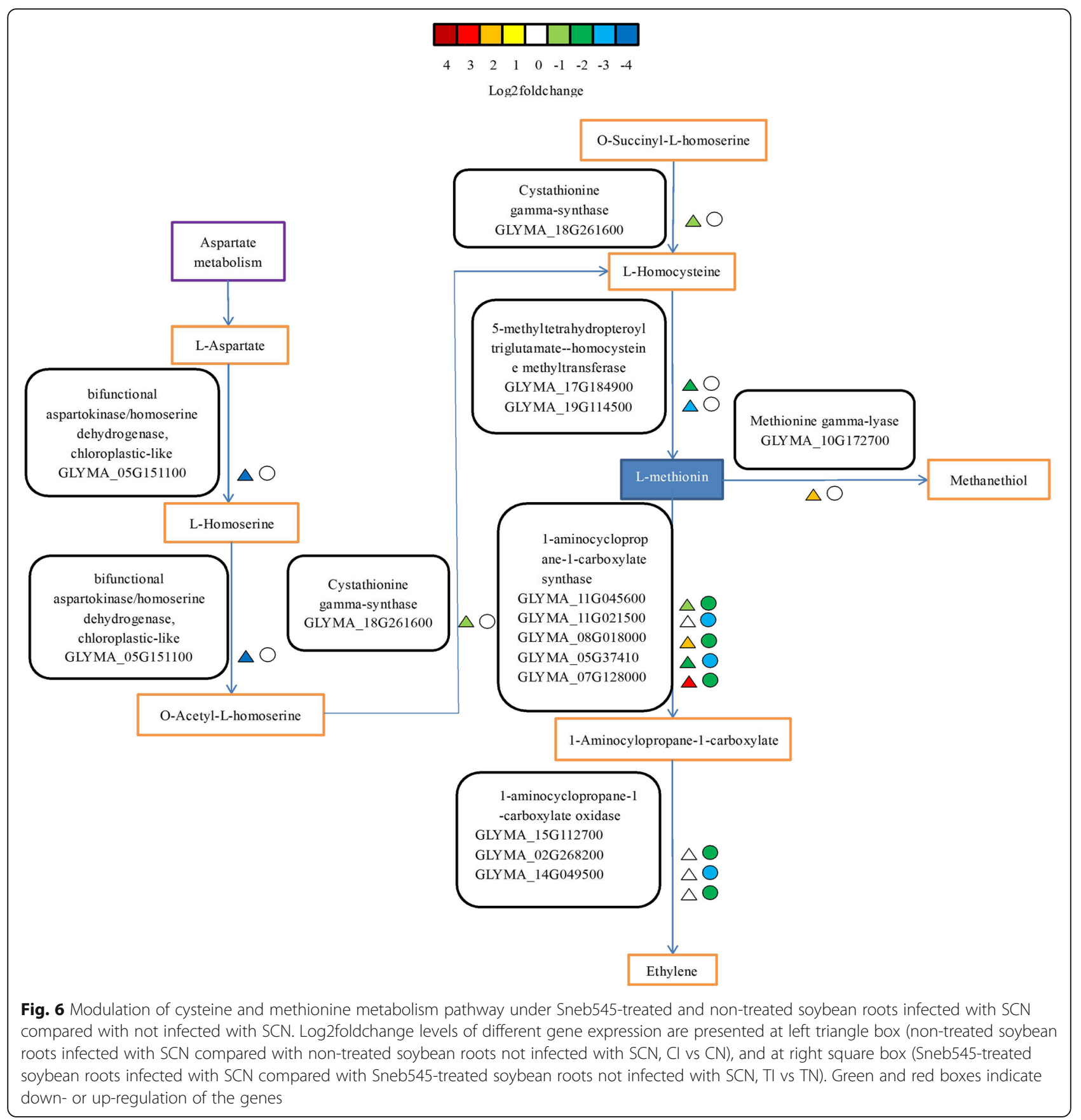

vinylphenol (1000 $\left.\mu \mathrm{g} \quad \mathrm{ml}^{-1}\right)$ and piperine $\left(600 \mu \mathrm{g} \mathrm{ml}^{-1}\right)$, the corrected nematode mortality rates were $82.8,77.8,87.9$, and $79.9 \%$, respectively.

\section{Discussion}

Information on the effectiveness of B. simplex as a biocontrol agent against $\mathrm{SCN}$ is limited. Our previous study showed that B. simplex strain Sneb545 increases soybean resistance to SCN. Thus, our objective in the present study was to conduct a combined metabolomic and transcriptomic analysis to gain information regarding the biological mechanism of soybean defence enhancement to SCN via Sneb545 treatment. The results showed that Sneb545 modulated the accumulation of 4vinylphenol, L-methionine, piperine, and palmitic acid in soybean roots under SCN infection. Our nematode mortality assessment showed that 4-vinylphenol has nematicidal activity against $\mathrm{SCN}$ at a minimum effective concentration of $1000 \mu \mathrm{g} \mathrm{ml}^{-1}$ (Table 1). These results were in agreement with those reported in a previous study and revealed the nematicidal activity of 4vinylphenol against Caenorhabditis elegans in three 


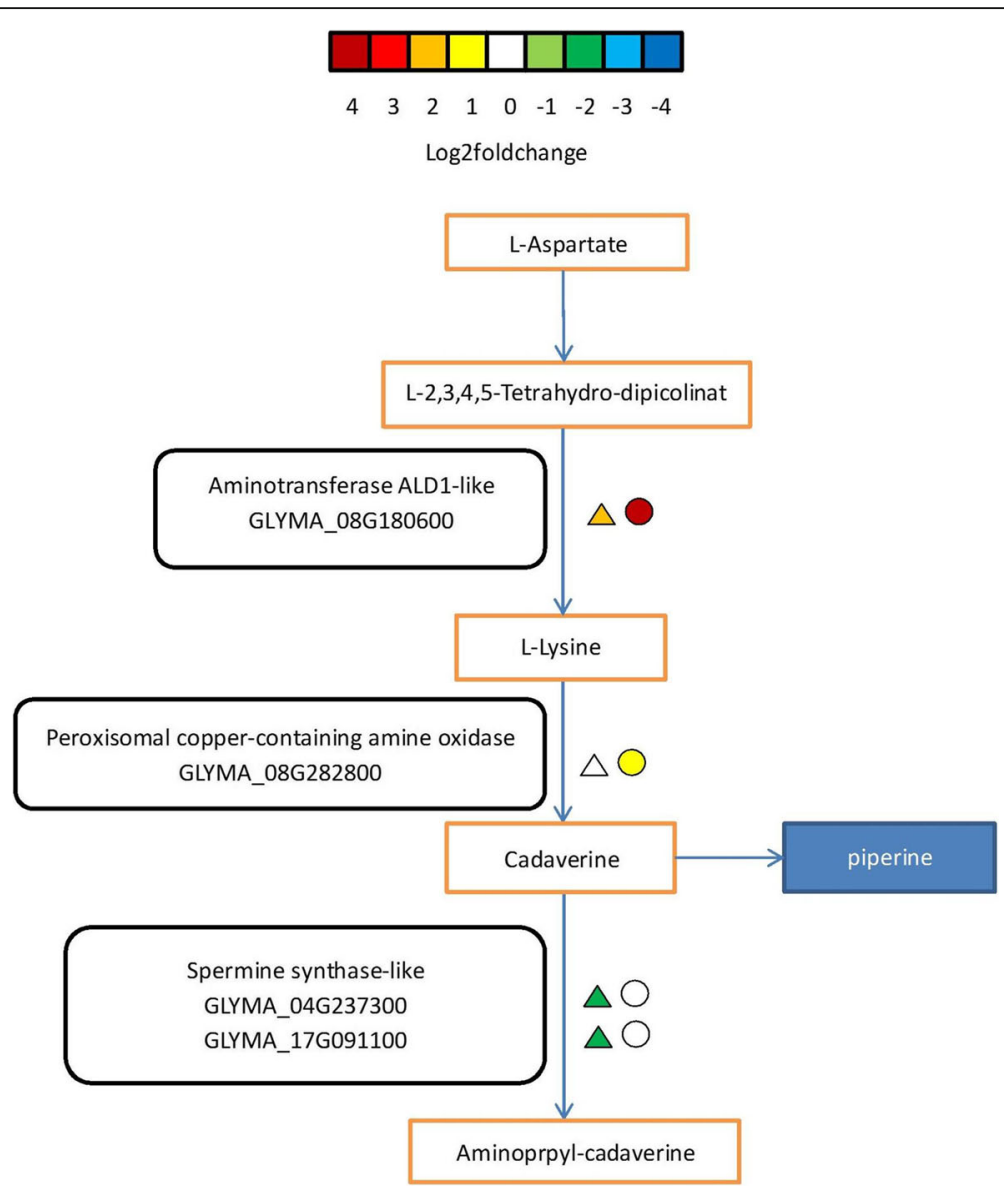

Fig. 7 Modulation of tropane, piperidine and pyridine alkaloid biosynthesis metabolism pathway under Sneb545-treated and non-treated soybean roots infected with SCN compared with not infected with SCN. Log2foldchange levels of different gene expression are presented at left triangle box (non-treated soybean roots infected with SCN compared with non-treated soybean roots not infected with SCN, Cl vs CN), and at right square box (Sneb545-treated soybean roots infected with SCN compared with Sneb545-treated soybean roots not infected with SCN, TI vs TN). Green and red boxes indicate down- or up-regulation of the genes

Rosaceae species at a minimum effective concentration of $600 \mu \mathrm{g} \mathrm{ml}^{-1}$ [36]. Based on our metabolomic data, the levels of 4-vinylphenol were higher in TI than in CI (Additional file 8: Table S4), indicating that Sneb545 induced the accumulation of 4-vinylphenol, improving soybean resistance against SCN.

In the phenylpropanoid biosynthesis pathway, PAL plays an important role in plant defence [37-39]; CAD is an indicator of lignin biosynthesis and plays an important role in plant responses to biotic and abiotic stresses [40-43]; 4CL is often associated with induced defence [43]; whereas POD functions as a scavenger of reactive oxygen species typically produced as an early plant resistance response against a wide range of pathogens and may be involved in blocking oxidant-mediated programmed cell death [44, 45]. Previous microarray studies have indicated that SCN infection of susceptible soybeans leads to the suppression of PAL and 4CL genes and the up-regulation of CAD and POD genes
[46-51]. Similar changes in gene expression were identified in the CI vs. CN group but not in the TI vs. TN group, suggesting that Sneb545 might induce soybean resistance to $\mathrm{SCN}$.

In the cysteine and methionine pathway, many genes play important roles in plant defence against nematode infection. Our nematode mortality assessment showed that methionine has nematicidal activity at a minimum effective concentration of $500 \mu \mathrm{g} \mathrm{ml}^{-1}$ (Table 1). These results were in agreement with those reported in a previous study and revealed the nematicidal activity of methionine against Belonolaimus longicaudatus Rau (Belonolaimidae) and Mesocriconema ornata Raski (Criconematidae) [52, 53]. Both transcriptomic and metabolomic analysis demonstrated that Sneb545 induced the accumulation of methionine under SCN infection. MGL that is a key gene in sulfur amino acid degradation [54] was suppressed in TI, inhibiting L-methionine degradation. The precursor of ethylene, 1-aminocyclopropatie-1-carboxylate (ACC), is 


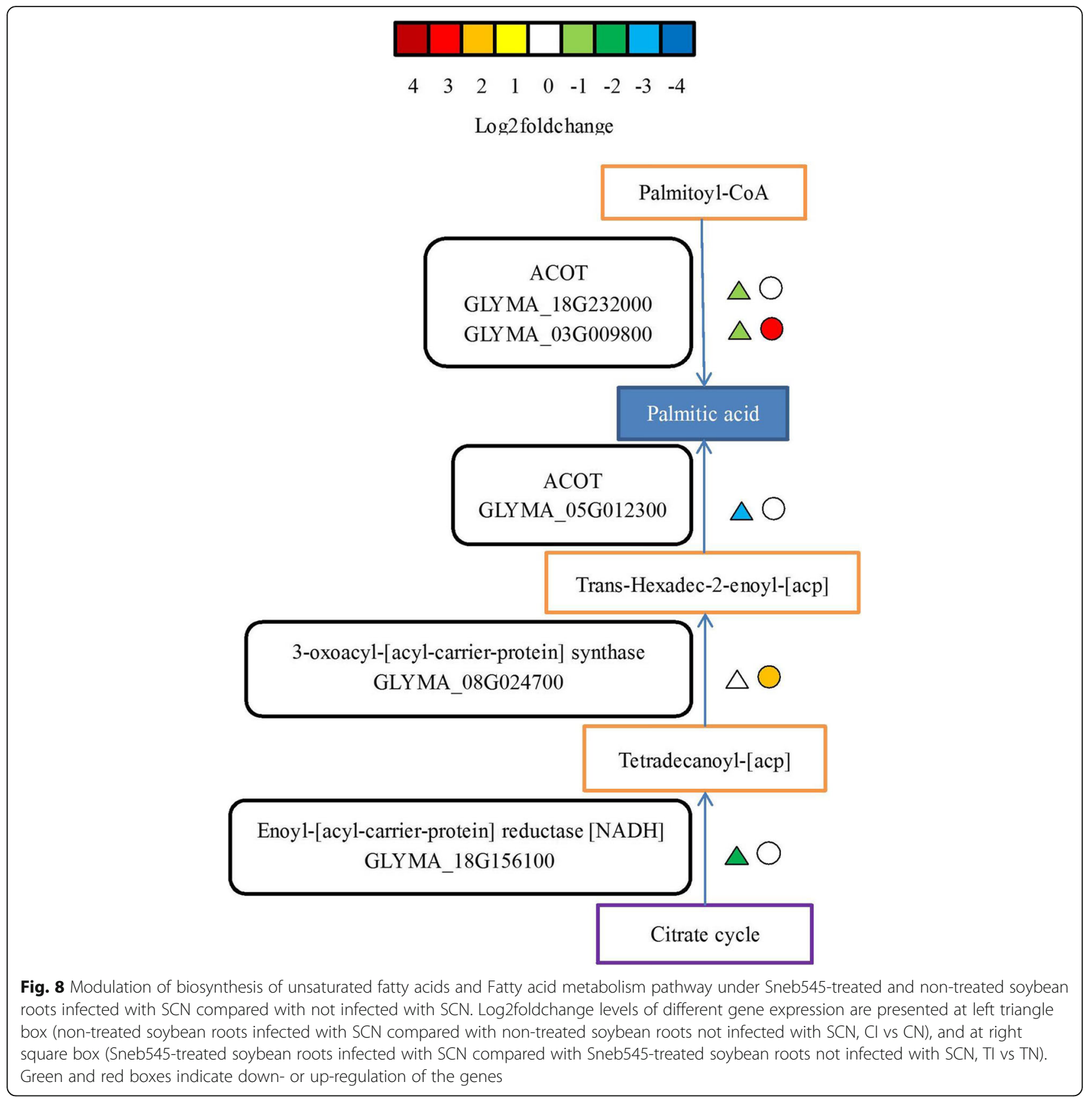

produced by the conversion of S-adenosyl-Met by ACS [55], whereas ACO is responsible for the final stage of ethylene production in higher plants [56]. Arabidopsis mutants that overproduced ethylene or wild-type plants treated with ACC showed an increased number of female nematodes in the roots [57]. Similarly, a soybean mutant sensitive to ethylene showed a $50 \%$ decrease in the number of SCN in the roots [58]. In the present study, $\mathrm{ACS}$ and $\mathrm{ACO}$ were down-regulated in $\mathrm{TN}$, improving soybean resistance against SCN. Additionally, bifunctional AK-HSDH I and II that catalyse L-aspartic acid, which synthesises is L-methionine [59]. MET6 that converts homocysteine to L-methionine [60]; and CGS that participates in the biosynthesis of methionine [61, 62] were up-regulated in $\mathrm{TN}$, enhancing the accumulation of $\mathrm{L}$ methionine and consequently, the resistance against $\mathrm{SCN}$.

In the present study, the nematode mortality assessment showed that piperine has nematicidal activity at a minimum effective concentration of $600 \mu \mathrm{g} \mathrm{ml} \mathrm{m}^{-1}$ (Table 1). These results were in agreement with those reported in a previous study and revealed the nematicidal activity of piperine against Meloidogyne javanica by inhibiting the function of glutathione $\mathrm{S}$ transferase [63, 64]. In the tryptophan, piperidine, and 
Table 1 Effects of metabolites from commercial sources at $48 \mathrm{~h}$ corrected death. rate on soybean cyst nematode second-stage juveniles (J2)

\begin{tabular}{ll}
\hline Treatment & 48 h Corrected J2 death rate (\%) \\
\hline L-methionine $^{\mathrm{a}}(500 \mu \mathrm{g} / \mathrm{ml})$ & $82.8 \pm 0.01$ \\
Palmitic acid $^{\mathrm{b}}(600 \mu \mathrm{g} / \mathrm{ml})$ & $77.8 \pm 0.01$ \\
4-vinylphenol $^{\mathrm{b}}(600 \mu \mathrm{g} / \mathrm{ml})$ & $87.9 \pm 0.02$ \\
Piperine $^{\mathrm{c}}(1000 \mu \mathrm{g} / \mathrm{ml})$ & $79.9 \pm 0.02$
\end{tabular}

Means of twelve replicates with the same letter do not differ significantly $(P \leq 0.05)$ (the mean of corrected death rate $\pm \mathrm{SE}$ )

aL-methionine was dissolved in water and the water as the control

${ }^{b}$ Palmitic acid and 4-vinylphenol were dissolved in 3\% Tween 80 and $4 \%$

ethanol, at the same time $3 \%$ Tween 80 and $4 \%$ ethanol as the control

'Piperine was dissolved in 3\% Tween 80 and $4 \%$ methanol, at the same time

$3 \%$ Tween 80 and $4 \%$ methanol as the control

pyridine alkaloid pathway, $\mathrm{CuAO}$ catalyses the oxidation of primary alcohol groups of amino acids to the corresponding amino aldehydes with the concomitant production of $\mathrm{H} 2 \mathrm{O} 2$ and $\mathrm{NH} 3$ [65]. CuAO shows differential localization in the apoplast and peroxisomes, but in both locations, it contributes to modulating plant defence against different types of stress [66]. In pea, the resistant cultivar P665 showed increased levels of peroxisomal $\mathrm{CuAO}$ under Meloidogyne pinodes infection compared with those of the susceptible cultivar Messire [67]. Spermidine synthase is a key enzyme involved in polyamine biosynthesis as a specific 10A06 interactor. Previous studies showed that SPDS2 promoter is strongly activated in the nematode-induced syncytia, and transgenic plants overexpressing SPDS2 have enhanced susceptibility to Heterodera schachtii [68]. ALD1 encodes aminotransferases that act on an overlapping set of amino acids in vitro [69] and may be a key component in disease resistance by the regulation of nematicidal metabolites [70, 71]. In the present study, CuAO and ALD1 were up-regulated, whereas SPDS was suppressed in the TI vs. TN group, improving soybean resistance against SCN (Additional file 8: Table S4).

The nematode mortality assessment in the present study showed that palmitic acid has nematicidal activity at a minimum effective concentration of $600 \mu \mathrm{g} \mathrm{ml} \mathrm{m}^{-1}$ (Table 1). Similarly, a previous study showed that a nematicidal fatty acid mixture obtained from Hericium coralloides exhibited both repellent and nematicidal effects on C. elegans [72]. Palmitic acid identified in the benzene root extracts of Iris japonica also showed nematicidal properties [73]. In the unsaturated fatty acid biosynthesis and fatty acid metabolism pathways, acylCoA thioesterase (ACOT) shows the highest rate of hydrolysis with palmitoyl-CoA and forms palmitic acid [74]; acyl-ACP thioesterase (FATA) is a chain-lengthdetermining enzyme in the de novo biosynthesis of fatty acids in plants; 3-oxoacyl-[acyl-carrier-protein] synthase facilitates the condensation reaction of fatty-acid synthesis by increasing an acyl acceptor of two carbons from malonyl-ACP, resulting in the elongation from $\mathrm{C}$ 10 to unsaturated $\mathrm{C}-16$ and $\mathrm{C}-18$ fatty acids [75]; and ENR stimulates a key regulatory step in fatty acid biosynthesis [76]. In the present study, ACOT, FATA, 3oxoacyl-[acyl-carrier-protein] synthase, and ENR showed different expression profiles in the TI vs. TN and CI vs. $\mathrm{CN}$ groups and revealed that Sneb545 induced the accumulation of palmitic acid in the former group improving its resistance against $\mathrm{SCN}$.

The identification of a parasite by the roots can induce a hypersensitive reaction, leading to the discharge of nematicidal compounds such as alkaloids, terpenes, phenols, and amino acids [77-79]. Here, we showed that Sneb545 could induce the production of nematicidal compounds that inhibit the growth of nematodes in the soybean root.

\section{Conclusion}

To better understand the Sneb545-induced soybean resistance to $\mathrm{SCN}$, we performed a combined transcriptomic and metabolomic analysis to identify any differences in gene expression and secondary metabolites between Sneb545-treated and non-treated soybeans under SCN infection. Our results showed that phenylpropanoid biosynthesis, cysteine and methionine metabolism, tropane, piperidine, and pyridine alkaloid biosynthesis, unsaturated fatty acid biosynthesis, and fatty acid metabolism might participate in the Sneb545-induced soybean response to SCN. Additionally, we revealed that Sneb545-treated soybeans accumulated four nematicidal metabolites (4-vinylphenol, L-methionine, piperine, and palmitic acid) that inhibited SCN development. However, further studies are needed to evaluate the effectiveness of accumulated nematicidal metabolite application as a biological control measure against SCN.

\section{Additional files}

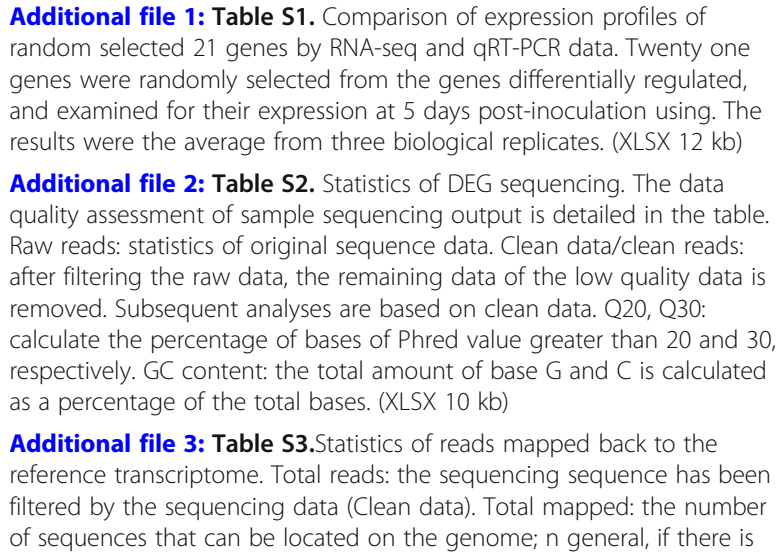
genes were randomly selected from the genes differentially regulated, and examined for their expression at 5 days post-inoculation using. The results were the average from three biological replicates. (XLSX 12 kb)

Additional file 2: Table S2. Statistics of DEG sequencing. The data quality assessment of sample sequencing output is detailed in the table. Raw reads: statistics of original sequence data. Clean data/clean reads: after filtering the raw data, the remaining data of the low quality data is removed. Subsequent analyses are based on clean data. Q20, Q30: calculate the percentage of bases of Phred value greater than 20 and 30, respectively. GC content: the total amount of base $\mathrm{G}$ and $\mathrm{C}$ is calculated as a percentage of the total bases. (XLSX $10 \mathrm{~kb}$ )

Additional file 3: Table S3.Statistics of reads mapped back to the reference transcriptome. Total reads: the sequencing sequence has been filtered by the sequencing data (Clean data). Total mapped: the number of sequences that can be located on the genome; $n$ general, if there is 
no pollution and the reference genome is appropriate, the percentage of this data is greater than 70\%. (XLSX 9 kb)

Additional file 4: Figure S1. Differentially expressed genes enriched KEGG pathway in $\mathrm{Cl}$ vs CN group. (JPG $172 \mathrm{~kb}$ )

Additional file 5: Figure S2. Differentially expressed genes enriched KEGG pathway in TI vs TN group. (JPG $176 \mathrm{~kb}$ )

Additional file 6: Table S5. Metabolites enriched into twenty different metabolic pathways. (XLSX $11 \mathrm{~kb}$ )

Additional file 7: Table S6. Comprehensive networks of metabolites and transcripts, changed in common KEGG pathways and differentially expressed genes among these pathways. (XLSX $13 \mathrm{~kb}$ )

Additional file 8: Table S4. Entire data set for metabolite profiling from different treatment soybean roots. (XLSX $10 \mathrm{~kb}$ )

\section{Abbreviations}

4CL: 4-coumarate: coenzyme Aligase; ACC: 1-Aminocyclopropatie-1carboxylate; ACO: 1-Aminocyclopropatie-1-carboxylate oxidase; ACOT: AcylCoA thioesterase; ACS: 1-Aminocyclopropatie-1-carboxylatesynthase; bifunctional AK-HSDH: bifunctional enzymes aspartokinase-homoserine dehydrogenase; CAD: Cinnamyl alcohol dehydrogenase; CYP: Cytochrome P450; GC-MS: Gas chromatography-mass spectrometry; ISR: Induction of systemic resistance; MGL: Methionine gamma-lyase; OPLS-DA: Orthogonal projections to latent structures-discriminate analysis; PAL: Phenylalanine ammonia-lyase; PGPR: Plant growth-promoting rhizobacteria; POD: Peroxidases: SCN: Soybean cyst nematode; VIP: Variable importance projection

\section{Acknowledgments}

This study was supported by the National Nature Science Fund Key Projects (313300630) and China Agriculture Research System (No. CARS-04-PS13).

\section{Availability of data and materials}

All the data pertaining to the present study has been included in table and/or figure form in the present manuscript and authors are pleased to share analyzed/ raw data and plant materials upon reasonable request. All raw sequence reads have been deposited in NCBI Sequence Read Archive (http://www.ncbi.nlm.nih.gov/sra). The BioProject and SRA accession are PRJNA436822 and SRR6802829, SRR6804651, SRR6805032, SRR6808244 respectively.

\section{Authors' contributions}

WK designed and performed research, analyzed data and wrote the manuscript. XZ, YW and LC participated in the design of the study. YD designed research and revised the manuscript. All the authors have read and approved the final manuscript.

\section{Ethics approval and consent to participate}

Not applicable

\section{Competing interests}

The authors declare that they have no competing interests.

\section{Publisher's Note}

Springer Nature remains neutral with regard to jurisdictional claims in published maps and institutional affiliations.

\section{Author details}

${ }^{1}$ Nematology Institute of Northern China, Shenyang Agricultural University, No.120 Dongling Road, Shenyang 110866, China. ${ }^{2}$ Institute of Biotechnology, Shenyang Agricultural University, No.120 Dongling Road, Shenyang 110866, China.

Received: 26 December 2017 Accepted: 30 April 2018 Published online: 11 May 2018

\section{References}

1. Wrather JA, Anand SC, Dropkin VH. Soybean cyst nematode control. Plant Dis. 1984;68(9):829-33.

2. Akhtar M, Mahmood I. Control of plant-parasitic nematodes with organic and inorganic amendments in agricultural soil. Appl Soil Ecol. 1996;4(4):243-7.
3. Akhtar M. Current options in integrated management of plant-parasitic nematodes. Integr Pest Manag Rev. 1997;2(4):187-97.

4. Lacey LA, Frutos R, Kaya HK, Vail P. Insect pathogens as biological control agents: do they have a future. Biol Control. 2001;21(3):230-48.

5. Choudhary DK, Johri BN. Interactions of Bacillus spp. and plants-with specia reference to induced systemic resistance (ISR). Microbiol Res. 2009;164(5): 493-513.

6. Ryu CM, Hu CH, Reddy MS, Kloepper JW. Different signaling pathways of induced resistance by rhizobacteria in Arabidopsis thaliana against two pathovars of Pseudomonas syringae. New Phytol. 2003;160(2):413-20.

7. Emmert EAB, Handelsman J. Biocontrol of plant disease: a (gram-) positive perspective. FEMS Microbiol Lett. 1999;171(1):1-9.

8. Siddiqui ZA, Mahmood I. Role of bacteria in the management of plant parasitic nematodes: a review. Bioresour Technol. 1999;69(2):167-79.

9. Meyer SL. United States Department of Agriculture-Agricultural Research Service research programs on microbes for management of plant-parasitic nematodes. Pest Manag Sci. 2003:59(6-7):665-70.

10. Sikora RA. Interrelationship between plant health promoting rhizobacteria, plant parasitic nematodes and soil microorganisms. In: Internationaal symposium over Fytofarmacie En Fytiatrie; 1988

11. Raupach GS, Kloepper JW. Mixtures of plant growth-promoting rhizobacteria enhance biological control of multiple cucumber pathogens. Phytopathology. 1998;88(11):1158-64.

12. Ongena M, Duby F, Jourdan E, Beaudry $T$, Jadin V, Dommes J, Thonart P. Bacillus subtilis M4 decreases plant susceptibility towards fungal pathogens by increasing host resistance associated with differential gene expression. Appl Microbiol Biotechnol. 2005;67(5):692-8.

13. Ryu CM, Farag MA, Hu CH, Reddy MS, Kloepper JW, Paré PW. Bacterial volatiles induce systemic resistance in Arabidopsis. Plant Physiol. 2004;134(3):1017-26.

14. Xiang $P$, Chen L, Zhu X, Wang Y, Duan Y. Screening and identification of bacterium to induce resistance of soybean against Heterodera glycines. Chinese J Biol Control. 2013:29(4):661-5.

15. Hagemeier J, Schneider B, Oldham NJ, Hahlbrock K. Accumulation of soluble and wall-bound indolic metabolites in Arabidopsis thaliana leaves infected with virulent or avirulent Pseudomonas syringae pathovar tomato strains. Proc Natl Acad Sci. 2001;98(2):753-8.

16. Desbrosses GG, Kopka J, Udvardi MK. Lotus japonicus metabolic profiling. Development of gas chromatography-mass spectrometry resources for the study of plant-microbe interactions. Plant Physiol. 2005;137(4):1302-18.

17. William AJ, Ellis DI, Heald JK, Royston G, Mur LAJ. Metabolomic approaches reveal that phosphatidic and phosphatidyl glycerol phospholipids are major discriminatory non-polar metabolites in responses by Brachypodium distachyon to challenge by Magnaporthe grisea. Plant Journal for Cell \& Molecular Biology. 2006:46(3):351.

18. Berger S, Sinha AK, Roitsch T. Plant physiology meets phytopathology: plant primary metabolism and plant-pathogen interactions. J Exp Bot. 2007; 58(15-16):4019-26.

19. Ward JL, Forcat S, Beckmann M, Bennett M, Miller SJ, Baker JM, Hawkins ND, Vermeer CP, Lu C, Lin W. The metabolic transition during disease following infection of Arabidopsis thaliana by Pseudomonas syringae pv. Tomato. Plant J. 2010;63(3):443-57.

20. Bazzini AA, Manacorda CA, Tohge T, Conti G, Rodriguez MC, Nunes-Nesi A, Villanueva S, Fernie AR, Carrari F, Asurmendi S. Metabolic and miRNA profiling of TMV infected plants reveals biphasic temporal changes. PLoS One. 2011:6(12):e28466.

21. Colebatch G, Desbrosses G, Ott T, Krusell L, Montanari O, Kloska S, Kopka J, Udvardi MK. Global changes in transcription orchestrate metabolic differentiation during symbiotic nitrogen fixation in Lotus japonicus. Plant J. 2004;39(4):487-512.

22. Parker D, Beckmann M, Zubair H, Enot DP, Caracuel-Rios Z, Overy DP, Snowdon S, Talbot NJ, Draper J. Metabolomic analysis reveals a common pattern of metabolic re-programming during invasion of three host plant species by Magnaporthe grisea. Plant J. 2009;59(5):723-37.

23. Chen $L$, Zhu $X$, Wang $Y$, Chen $L$, Duan $Y$. Proteomic analysis of the bacterial induction of resistance to atrazine in soybean leaves. Acta Physiol Plant. 2014;36(8):2229-41.

24. Mazarei M, Liu W, Alahmad H, Arelli PR, Pantalone VR, Jr CNS. Gene expression profiling of resistant and susceptible soybean lines infected with soybean cyst nematode. Theoretical \& Applied Genetics. 2011;123(7):1193.

25. Xu Y, Niblack TL. A new classification scheme for genetically diverse populations of Heterodera glycines. J Nematol. 2002;34(4):279-88. 
26. Macguidwin AE, Bird GW, Safir GR. Influence of Glomus fasciculatum on Meloidogyne hapla infecting Allium cepa. J Nematol. 1985;17(4):389.

27. Langmead B, Salzberg SL. Fast gapped-read alignment with bowtie 2. Nat Methods. 2012:9(4):357.

28. Kim D, Pertea G, Trapnell C, Pimentel H, Kelley R, Salzberg SL. TopHat2: accurate alignment of transcriptomes in the presence of insertions, deletions and gene fusions. Genome Biol. 2013;14(4):R36.

29. Trapnell C, Williams BA, Pertea G, Mortazavi A, Kwan G, van Baren MJ, Salzberg SL, Wold BJ, Pachter L. Transcript assembly and quantification by RNA-Seq reveals unannotated transcripts and isoform switching during cell differentiation. Nat Biotech. 2010;28(5):511-5.

30. Xie C, Mao X, Huang J, Ding Y, Wu J, Dong S, Kong L, Gao G, Li CY, Wei L. KOBAS 2.0: a web server for annotation and identification of enriched pathways and diseases. Nucleic Acids Res. 2011;39(Web Server issue):W316

31. Mao X, Tao C, Olyarchuk JG, Wei L. Automated genome annotation and pathway identification using the KEGG Orthology (KO) as a controlled vocabulary. Bioinformatics. 2005;21(19):3787-93.

32. Livak K, Schmittgen TD. Analysis of relative gene expression data using realtime quantitative PCR and the $2-\Delta \Delta C$ T method. Methods. 2012;25(4):402-8.

33. Lisec J, Schauer N, Kopka J, Willmitzer L, Fernie AR. Gas chromatography mass spectrometry-based metabolite profiling in plants. Nat Protoc. 2006;1(1):387.

34. Kind T, Wohlgemuth G, Lee DY, Lu Y, Palazoglu M, Shahbaz S, Fiehn O FiehnLib: mass spectral and retention index libraries for metabolomics based on quadrupole and time-of-flight gas chromatography/mass spectrometry. Anal Chem. 2009;81 (24):10038-48.

35. Xiang N, Lawrence KS. Optimization of in vitro techniques for distinguishing between live and dead second stage juveniles of Heterodera glycines and Meloidogyne incognita. PLoS One. 2016;11(5):e0154818.

36. Yoshizawa Y, Kawaii S, Kanauchi M, Chida M, Mizutani J. Chavicol and related compounds as Nematocides. Biosci Biotechnol Biochem. 2008;57(9): $1572-4$.

37. Kim DS, Hwang BK. An important role of the pepper phenylalanine ammonia-lyase gene (PAL1) in salicylic acid-dependent signalling of the defence response to microbial pathogens. J Exp Bot. 2014;65(9):2295-306.

38. Mauch-Mani B, Slusarenko AJ. Production of salicylic acid precursors is a major function of phenylalanine ammonia-lyase in the resistance of Arabidopsis to Peronospora parasitica. Plant Cell. 1996;8(2):203-12.

39. MacDonald MJ, D'Cunha GB. A modern view of phenylalanine ammonia lyase. Biochem Cell Biol. 2007;85(3):273-82.

40. Walter MH, Grima-Pettenati J, Grand C, Boudet AM, Lamb CJ. Cinnamylalcohol dehydrogenase, a molecular marker specific for lignin synthesis: CDNA cloning and mRNA induction by fungal elicitor. Proc Natl Acad Sci U S A. 1988:85(15):5546.

41. Galliano $\mathrm{H}$, Heller W, Jr HS. Ozone induction and purification of spruce cinnamyl alcohol dehydrogenase. Phytochemistry. 1993;32(3):557-63.

42. Campbell MM, Ellis BE. Fungal elicitor-mediated responses in pine cell cultures : I. Induction of phenylpropanoid metabolism. Plant Physiol. 1992; 31(3):737-42.

43. Uhlmann A, Ebel J. Molecular cloning and expression of 4-coumarate: coenzyme a ligase, an enzyme involved in the resistance response of soybean (Glycine max L.) against pathogen attack. Plant Physiol. 1993;102(4):1147-56.

44. Blokhina O, Virolainen E, Fagerstedt KV. Antioxidants, oxidative damage and oxygen deprivation stress: a review. Ann Bot. 2003;91(2):179.

45. Marrs KA. The functions and regulation of glutathione s-transferases in plants. Annual Review of Plant Physiology \& Plant Molecular Biology. 1996; 47(47):127.

46. Alkharouf NW, Matthews BF. Timecourse microarray analyses reveal global changes in gene expression of susceptible Glycine max (soybean) roots during infection by Heterodera glycines (soybean cyst nematode). Planta. 2006;224(4):838-52.

47. Ithal N, Recknor J, Nettleton D, Hearne L, Maier T, Baum TJ, Mitchum MG Parallel genome-wide expression profiling of host and pathogen during soybean cyst nematode infection of soybean. Mol Plant-Microbe Interact. 2007;20(3):293

48. Ithal N, Recknor J, Nettleton D, Maier T, Baum TJ, Mitchum MG. Developmental transcript profiling of cyst nematode feeding cells in soybean roots. Mol Plant-Microbe Interact. 2007;20(5):510.

49. Klink VP, Overall CC, Alkharouf NW, Macdonald MH, Matthews BF. A timecourse comparative microarray analysis of an incompatible and compatible response by Glycine max (soybean) to Heterodera glycines (soybean cyst nematode) infection. Planta. 2007;226(6):1423.
50. Klink VP, Overall CC, Alkharouf NW, Macdonald MH, Matthews BF. Laser capture microdissection (LCM) and comparative microarray expression analysis of syncytial cells isolated from incompatible and compatible soybean (Glycine max) roots infected by the soybean cyst nematode (Heterodera glycines). Planta. 2007;226(6):1389-409.

51. Puthoff DP, Ehrenfried ML, Vinyard BT, Tucker ML. GeneChip profiling of transcriptional responses to soybean cyst nematode, Heterodera glycines, colonization of soybean roots. J Exp Bot. 2007;58(12):3407.

52. Zhang Y: Evaluation of amino acids against Belonolaimus Longicaudatus. 2010.

53. Lewis DS, Cuda JP, Stevens BR. A novel biorational pesticide: efficacy of methionine against Heraclides (Papilio) cresphontes, a surrogate of the invasive Princeps (Papilio) demoleus (Lepidoptera: Papilionidae). J Econ Entomol. 2011;104(6):1986-90.

54. Tokoro M, Asai T, Kobayashi S, Takeuchi T, Nozaki T. Identification and characterization of two isoenzymes of methionine gamma-lyase from Entamoeba histolytica: a key enzyme of sulfur-amino acid degradation in an anaerobic parasitic protist that lacks forward and reverse trans-sulfuration pathways. J Biol Chem. 2003;278(43):42717-27.

55. Adams DO, Yang SF. Ethylene biosynthesis: identification of 1aminocyclopropane-1-carboxylic acid as an intermediate in the conversion of methionine to ethylene. Proc Natl Acad Sci U S A. 1979;76(1):170.

56. John P. Ethylene biosynthesis: the role of 1-aminocyclopropane-1carboxylate (ACC) oxidase, and its possible evolutionary origin. Physiol Plant. 1997;100(3):583-92.

57. 2Nd WM, Su H, Rodermel SR, Baum TJ. Susceptibility to the sugar beet cyst nematode is modulated by ethylene signal transduction in Arabidopsis thaliana. Mol Plant-Microbe Interact. 2001;14(10):1206.

58. Bent AF, Hoffman TK, Schmidt JS, Hartman GL, Hoffman DD, Xue P, Tucker ML. Disease- and performance-related traits of ethylene-insensitive soybean. Crop Science. 2006:46(2):893-901.

59. Truffabachi P, Veron M, Cohen GN. Structure, function, and possible origin of a bifunctional allosteric enzyme, Escherichia coli aspartokinase homoserine dehydrogenase I. Crc Crit Rev Biochem. 1974;2(3):379-415.

60. Whitfield CD, Jr SE, Weissbach H. Purification and properties of 5methyltetrahydropteroyltriglutamate-homocysteine transmethylase. J Biol Chem. 1970;245(2):390.

61. Guen LL, Thomas M, Kreis M. Gene density and organization in a small region of the Arabidopsis thaliana genome. Mol Gen Genet. 1994;245(3): 390-6.

62. Kim J, Leustek T. Cloning and analysis of the gene for cystathionine $y$ synthase from Arabidopsis thaliana. Plant Mol Biol. 1996;32(6):1117.

63. Parmar VS, Jain SC, Bisht KS, Jain R, Taneja P, Jha A, Tyagi OD, Prasad AK, Wengel J, Olsen CE. Phytochemistry of the genus piper. Phytochemistry. 1997:46(4):597-673.

64. Babu RO, Moorkoth D, Azeez S, Eapen SJ. Virtual screening and in vitro assay of potential drug like inhibitors from spices against glutathione-Stransferase of Meloidogyne incognita. Bioinformation. 2012;8(7):319.

65. Pietrangeli P, Federico R, B.Mondovì, Morpurgo L. Substrate specificity of copper-containing plant amine oxidases. J Inorg Biochem. 2007;101(7):9971004.

66. Planasportell J, Gallart M, Tiburcio AF, Altabella T. Copper-containing amine oxidases contribute to terminal polyamine oxidation in peroxisomes and apoplast of Arabidopsis thaliana. BMC Plant Biol. 2013;13(1):109.

67. Fondevilla S, Küster H, Krajinski F, Cubero Jl, Rubiales D. Identification of genes differentially expressed in a resistant reaction to Mycosphaerella pinodes in pea using microarray technology. BMC Genomics. 2011;12(1):28.

68. Hewezi T, Howe PJ, Maier TR, Hussey RS, Mitchum MG, Davis EL, Baum TJ. Arabidopsis spermidine synthase is targeted by an effector protein of the cyst nematode Heterodera schachtii. Plant Physiol. 2010;152(2):968-84.

69. Song JT, Lu H, Greenberg JT. Divergent roles in Arabidopsis thaliana development and defense of two homologous genes, aberrant growth and death2 and AGD2-LIKE DEFENSE RESPONSE PROTEIN1, encoding novel aminotransferases. Plant Cell. 2004;16(2):353-66.

70. Song J, Lu H, Mcdowell J, Greenberg Jt. A key role for ALD1 in activation of local and systemic defenses in Arabidopsis. Plant J. 2004;40(2):200-12.

71. Cecchini NM, Jung HW, Engle NL, Tschaplinski TJ, Greenberg JT. ALD1 regulates basal immune components and early inducible defense responses in Arabidopsis. Mol Plant-Microbe Interact. 2015;28(4):455.

72. Stadler M, Mayer A, Anke H, Sterner O. Fatty acids and other compounds with nematicidal activity from cultures of basidiomycetes. Planta Med. 1994; 60(2):128-32. 
73. Munakata K. Nematocidal natural products. Natural products for innovative pest management. 1983;2:299-311.

74. Wakil SJ. Fatty acid synthase, a proficient multifunctional enzyme. Biochemistry. 1989;28(11):4523-30.

75. Siggaardandersen M, Kauppinen S, Wettsteinknowles PV. Primary structure of a cerulenin-binding beta-ketoacyl-[acyl carrier protein] synthase from barley chloroplasts. Proc Natl Acad Sci U S A. 1991;88(10):4114-8.

76. Bergler $\mathrm{H}$, Fuchsbichler S, Högenauer G, Turnowsky F. The enoyl-[acyl-carrierprotein] reductase (Fabl) of Escherichia coli, which catalyzes a key regulatory step in fatty acid biosynthesis, accepts NADH and NADPH as cofactors and is inhibited by palmitoyl-CoA. Eur J Biochem. 1996;242(3):689-94.

77. Sano Z, Nakasono K, Araki M. Penetration and development of Meloidogyne incognita in some enemy and host plants. In: Proceedings of the Association for Plant Protection of Kyushu (Japan); 1983.

78. Gommers F. Biochemical interactions between nematodes and plants and their relevance to control. Helm Abstracts. 1981;50:9-24.

79. Tanda A, Atwal A, Bajaj Y. In vitro inhibition of root-knot nematode Meloidogyne incognita by sesame root exudate and its amino acids. Nematologica. 1989;35(1):115-24

Ready to submit your research? Choose BMC and benefit from:

- fast, convenient online submission

- thorough peer review by experienced researchers in your field

- rapid publication on acceptance

- support for research data, including large and complex data types

- gold Open Access which fosters wider collaboration and increased citations

- maximum visibility for your research: over $100 \mathrm{M}$ website views per year

At BMC, research is always in progress.

Learn more biomedcentral.com/submissions 